\title{
IMMUNOCYTOCHEMICAL ANALYSIS OF BLOOD LYMPHOCYTES IN UVEITIS
}

\author{
A. D. DICK, Y. F. CHENG, A. T. PURDIE, J. LIVERSIDGE, J. V. FORRESTER \\ Aberdeen
}

\begin{abstract}
SUMMARY
We studied the surface expression of activation markers IL2-R, HLA-DR and CD45-RO on peripheral T-lymphocytes in two groups of patients $(n=26)$ with idiopathic uveoretinitis, compared with controls. Thirteen patients were analysed by alkaline phosphatase anti-alkaline phosphatase (APAAP) immunocytochemistry, which demonstrated a significant rise in expression of HLA-DR and IL2-R surface markers. Flow cytometric analysis was performed on a further 13 patients, which confirmed a significant rise in IL2-R expression in uveitis patients. Within this group systemic activation was confined to patients with idiopathic retinal vasculitis. Dual flow cytometry confirmed a CD4+,IL2 - R+ T - lymphocyte phenotype. A further 4 patients with retinal vasculitis who had been treated with cyclosporin A demonstrated a $32 \%$ reduction in IL2-R expression over a 3-month period. Analysis of CD45-RO and CD5+ cells was found to be uninformative in this study. We have demonstrated activated peripheral lymphocytes in patients predominantly with retinal vasculitis, the significance of which is discussed.
\end{abstract}

Recent developments in the understanding of the pathophysiology of posterior uveitis have implicated CD4+ T-cells in the induction of the disease, as shown by studies of experimental uveoretinitis. ${ }^{1-3}$ To date, however, there are no systemic markers available to assess severity of the disease or the response to treatment. Previous unconfirmed studies have shown both raised immunoglobulin and circulating immune complexes in uveitis. ${ }^{4,5}$ Autoantibodies to retinal antigens have been detected but are also present in normal individuals, ${ }^{6}$ demonstrating a lack of sensitivity of present assays to detect an increase in autoreactive T-cells. More recently, in vitro cellular immune responses have been shown to occur with lymphocytes of uveitic patients to both IRBP and S-Ag and their fragments, ${ }^{7}$ indicating the wide range of autoantigens

Correspondence to: Professor J. V. Forrester, MD, FRCS, FCOphth, Department of Ophthalmology, Medical School, Aberdeen University, Foresterhill, Aberdeen AB9 2ZD, UK. involved. However, previous analyses of T- and B-cell subpopulations are largely reported to be unhelpful ${ }^{8}$ and general investigations of immune status yield little evidence of significant functional defects in cellular immunity. ${ }^{9}$ Recent reports of systemic T-cell activation, ${ }^{10}$ and the evidence of T-cell adhesion to retinal capillary endothelial cells, ${ }^{11}$ support the notion of systemic immunological activation leading to localised amplification of the immune system.

Therapeutic measures currently employed involve generalised immunosuppression and recently more specific immunomodulation with cyclosporin A. ${ }^{12-15}$ However, treatment is restricted by the side effects and resistance frequently observed with these therapies. Furthermore, relapses often occur on dose reduction as presently the only method of monitoring disease activity is by clinical assessment, which can be a poor representation of underlying immune activation.

In this study we examined 26 patients with idiopathic, endogenous uveoretinitis (both on and off treatment) to assess the degree of peripheral T-cell activation present and to identify possible systemic markers, if any, for monitoring disease activity and treatment response.

\section{METHODS}

\section{Subject Group}

Twenty-six patients with idiopathic posterior uveitis (unassociated with systemic disease, clinically or serologically) and 23 age-matched controls were studied in two groups described below (Table I). An additional 4 patients on cyclosporin A (CsA) therapy for treatment of retinal vasculitis were also studied by flow cytometric analysis. Patients were clinically graded on three separate components - anterior segment, vitreal and fundal examination as previously described. ${ }^{16,17}$ Controls had no clinical evidence of intraocular inflammation and no evidence of systemic disease. Patients' lymphocyte markers were analysed by two methods: alkaline phosphatase anti-alkaline phosphatase (APAAP) analysis (group A) and flow cytometric analysis (group B). 
Table I. Clinical data

\begin{tabular}{|c|c|c|c|c|c|}
\hline \multicolumn{3}{|c|}{ Group $\mathrm{A}^{\mathrm{a}}$} & \multicolumn{3}{|c|}{ Group $\mathrm{B}^{\mathrm{b}}$} \\
\hline $\begin{array}{l}\text { Patient } \\
\text { no. }\end{array}$ & Diagnosis & Treatment & $\begin{array}{l}\text { Patient } \\
\text { no. }\end{array}$ & Diagnosis & Treatment \\
\hline 1 & Pars planitis & Nil & 1 & Retinal vasculitis & $\mathrm{Nil}$ \\
\hline 2 & Retinal vasculitis & Steroid & 2 & Choroiditis & Steroid \\
\hline 3 & Pars planitis & Nil & 3 & Choroiditis & Steroid \\
\hline 4 & Pars planitis & Steroid & 4 & Retinal vasculitis & Nil \\
\hline 5 & Retinal vasculitis & Nil & 5 & Retinal vasculitis & Steroid \\
\hline 6 & Choroiditis & Nil & 6 & Retinal vasculitis & Steroid \\
\hline 7 & Retinal vasculitis & Nil & 7 & Retinal vasculitis & Steroid \\
\hline 8 & Choroiditis & Nil & 8 & Retinal vasculitis & Steroid \\
\hline 9 & Retinal vasculitis & Steroid & 9 & Retinal vasculitis & Nil \\
\hline 10 & Birdshot & Nil & 10 & Serpiginous & Steroid \\
\hline 11 & Birdshot & CsA & 11 & Retinal vasculitis & Nil \\
\hline 12 & Retinal vasculitis & CsA & 12 & Choroiditis & Steroid \\
\hline 13 & Serpiginous & Steroid & 13 & Choroiditis & Steroid \\
\hline
\end{tabular}

${ }^{a}$ APAAP analysis; ${ }^{b}$ flow cytometric analysis.

\section{APAAP Analysis}

Peripheral blood $(20 \mathrm{ml})$ was collected into acid-citratedextrose $(4: 1 \mathrm{v} / \mathrm{v})$. This was diluted $1: 1$ in sterile RPMI and layered onto Ficoll-Isopaque mixture $(6 \mathrm{ml}$ Ficol $+2.5 \mathrm{ml}$ Isopaque, density $1.007 \mathrm{~g} / \mathrm{ml}$; Pharmacia, Uppsala, Sweden. Lymphoid cells collected from the interface were suspended in RPMI $10 \%$ fetal calf serum (FCS) at $5 \times 10^{5}$ $\mathrm{ml}$ and $100 \mu \mathrm{l}$ of the suspension was spun onto clean, degreased microscope slides at 10000 r.p.m. for 5 minutes in a cytospin cytocentrifuge (Shandon Elliot, Cheshire, UK). An APAAP technique for cell staining using a panel of primary monoclonal antibodies (Table II) was employed. Rabbit anti-mouse immunoglobulin (DAKO) was used as the secondary antibody and APAAP (mouse) complexes (DAKO) as the tertiary antibodies. The cells were counterstained with haematoxylin. To increase the sensitivity of the technique further incubation with the secondary and tertiary antibodies was performed with IL2-R and CD19 antibodies. The percentage of positively stained lymphocytes was counted from a grid of 200 cells. Full blood counts and differential white cell counts (Coulter $\mathrm{S}$ plus profile) was also obtained.

Table II. Monoclonal markers used in APAAP and flow cytometric analysis

\begin{tabular}{lll}
\hline $\begin{array}{l}\text { Monoclonal } \\
\text { marker }\end{array}$ & Dilution & Activity \\
\hline CD25 (DAKO) & $1: 10$ & IL2-R \\
CD4 (DAKO/SAPU) & $1: 5$ & T-lymphocytes \\
CD8 (SAPU) & $1: 20$ & T-lymphocytes \\
CD19 (DAKO) & $1: 20$ & PAN B-cell \\
UCHM-1/CD14 (SAPU) & $1: 5$ & Monocyte \\
DA6: 164 & & HLA-DR B side chain \\
HLA-DR (DAKO) & $1: 20$ & except DR7 \\
CD45-RO (DAKO) & $1: 20$ & Immunocompetent \\
CD5 (DAKO) & $1: 20$ & T-cells \\
& & Activated B cells, \\
& & T-lymphocytes \\
\hline
\end{tabular}

Primary antibodies were directly conjugated with FITC, and secondary antibodies were indirectly conjugated with pre-labelled antibody.

${ }^{\mathrm{a}} \mathrm{K}$. Guy, Cytogenetics Department, Western General Hospital, Edinburgh.

\section{Flow Cytometry}

Lymphocytes were collected and separated as described above and concentrated to $1 \times 10^{7} / \mathrm{ml}$ in RPMI $10 \%$ FCS. Flow cytometric analysis was performed using a single cell suspension through an EPICS C flow cytometer (Coulter Electronics, Luton, UK). Cell populations were studied using both single and dual immunofluorescence with fluorescein isothiocyanate (FITC) and phycoerythrin (PE) conjugates. Monoclonal antibodies (Table II) were prepared in $50 \mu \mathrm{l}$ volumes of phosphate-buffered saline (PBS) containing 5\% heat-inactivated normal goat serum and $0.1 \%$ sodium azide, and incubated with $50 \mu \mathrm{l}$ of mononuclear cells for 40 minutes. For dual fluorescence the cells were further incubated with secondary PE-conjugated antibodies in 5\% normal goat serum and azide, then washed and resuspended in PBS. Background fluorescence was established with negative controls of PBS and monocyte markers (CD14-SAPU) and, in addition, for dual fluorescence positive controls of CD4+,CD19+ were used. Results are given as mean surface marker expression. Adequate staining was assessed by the mean peak channel, after background was set.

\section{Statistics}

Mean surface marker expression was expressed $\pm \mathrm{SD}$, for both patients and controls in the two groups. Student's $t$-test was used and probability values of $p<0.05$ were found significant.

\section{RESULTS}

Both APAAP $(n=13)$ and flow cytometric $(n=13)$ analysis of lymphocyte subsets demonstrated no significant difference in iridividual CD4, CD8 and B-cell populations between patients and controls. The CD4:CD8 ratio was significantly higher in the uveitis group of the APAAP study (patient $=2.3: 1 \pm 1.3$; control $=1.6: 1 \pm 0.63$; $p<0.05$ ), but this was not confirmed by flow cytometric analysis in the second group of patients. APAAP analysis of patients in group $\mathrm{A}(n=13)$ and controls $(n=13)$ showed a significantly raised circulating lymphocyte 
Table III. Percentage expression of activation markers HLA-DR and IL2-R in group A patients using APAAP technique.

\begin{tabular}{lccc}
\hline & $\begin{array}{c}\text { Control } \\
(\mathbf{n}=13)\end{array}$ & $\begin{array}{c}\text { Uveitis patients } \\
(n=13)\end{array}$ & $\begin{array}{c}\text { Uveitis patients, } \\
\text { no cyclosporin } \\
(n=10)\end{array}$ \\
\hline HLA-DR & $2.6 \pm 0.9$ & $13.8 \pm 3.5^{*}$ & $14.7 \pm 3.60^{*}$ \\
IL2-R & $0.64 \pm 0.29$ & $2.82 \pm 0.89$ & $3.06 \pm 0.90^{*}$ \\
\hline
\end{tabular}

Activation marker expression is given as a percentage of total cells sampled \pm SD. There was a significant increase in HLA-DR and IL2-R expression in the uveitis group $(* p<0.05)$. Ten patients with uveitis who were not on cyclosporin therapy demonstrated a greater IL2-R expression.

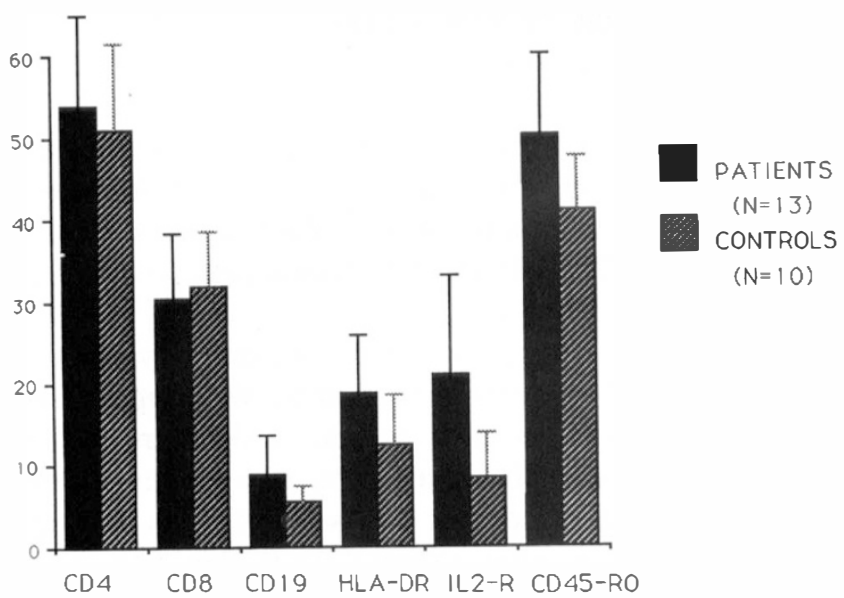

Fig. 1. Surface lymphocyte marker expression in patients with idiopathic uveoretinitis (group B) analysed by flow cytometry. Results are expressed as mean \% expression $\pm S D S$. There was an increase in IL2- $R$ expression in the patient group $(0.05>p>0.01)$. HLA-DR and CD45-RO were not raised significantly.

expression of HLA-DR $(p<0.05)$ in the patient group and IL2-R expression was significantly higher in uveitis patients who were not treated with cyclosporin A $(p<0.05$, Table III). CD45-RO was not analysed in this group of patients.

Flow cytometric analysis of patients in group $\mathrm{B}(n=13)$ also demonstrated a raised IL2-R expression compared with controls $(n=10)$ which was significant in the retinal vasculitis patients. No significant rise in HLA-DR expression was found. CD45-RO expression analysed in the flow cytometric group alone, again failed to demonstrate any significant rise in the patient group (Fig. 1). Dual flow cytometric analysis confirmed a CD4+,IL2-R+ phenotype. (Fig. 2). There was no increased expression on B-cells.

There was no significant correlation between disease activity (as established by the recently described uveitis grading system ${ }^{17}$ and either circulating HLA-DR or IL2-R expression. However, it must be emphasised that patients with active retinal vasculitis $(n=8)$ in the flow cytometric group, irrespective of extent of disease activity, demonstrated a greater expression of IL2-R (Fig. 3). Four patients with idiopathic retinal vasculitis who were treated with CsA demonstrated a $32 \%$ reduction in IL2-R expression after 3 months of treatment (Table IV).

\section{DISCUSSION}

Monitoring of many types of autoimmune and immunemediated diseases is currently being investigated by a search for an upregulation of 'activation markers' expressed on B- and T-lymphocytes in the circulation. Several markers of activation are now recognised, including HLA-DR, IL2-R and CD45-RO. HLA-DR antigens are class II major histocompatibility complex products found on the surface of cells that regulate immune responses and provoke allograft rejection. They are important for the recognition of self and in combination

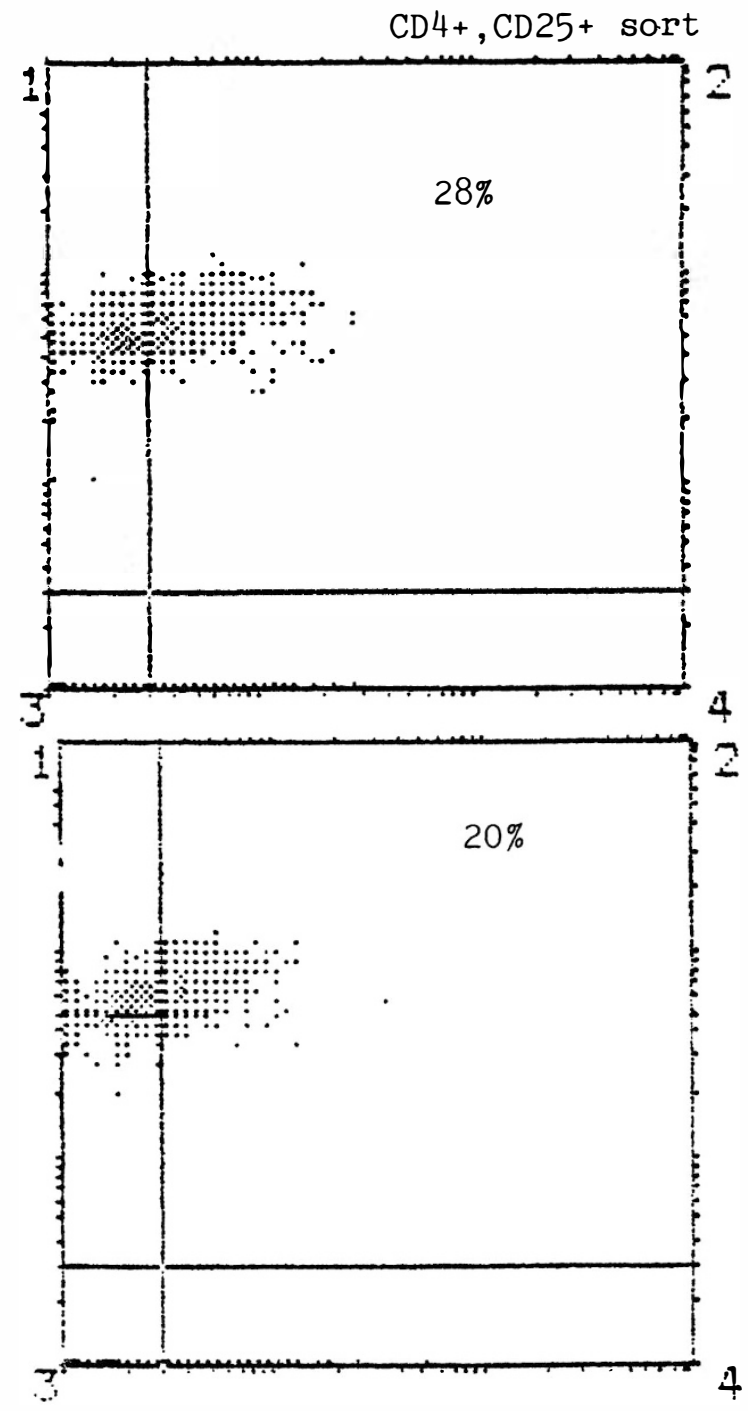

Fig. 2. Dual flow cytometric analysis of CD4 lymphocytes with $I L 2-R$ expression (IL2-R). The figure represents examples of dual fluorescence in two patients with retinal vasculitis (upper and lower traces respectively). Dual fluorescence is represented in a box diagram. Peripheral lymphocytes are cell sorted and stained with direct FITC-conjugated anti-CD4 antibody and indirect $P E$-labelled anti-CD25 antibody. Box 1 represents cells with $C D 4+, I L 2-R-$ phenotype. Box 2 represents cells with $C D 4+, I L 2-R+$ phenotype $(C D 4+, C D 25+$ sort $)$. Box 3 represents cells with $C D 4-, I L 2-R$ - phenotype, and box 4 represents cells with CD4-,IL2-R+ phenotype. The increased expression of IL2-R (CD25) in these two patient examples is situated on CD4+ T-lymphocytes $(28 \%$ and $20 \%$ of lymphocytes, respectively). 


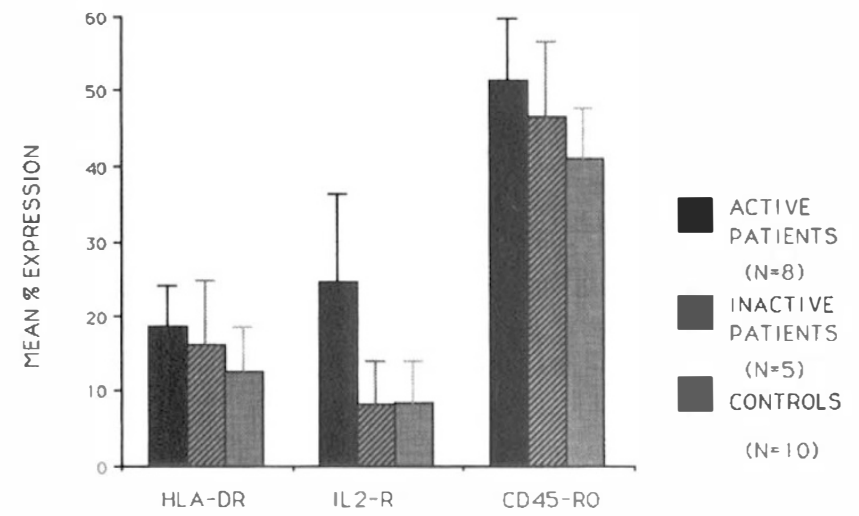

Fig. 3. Activation marker expression in patients (group B) with active idiopathic retinal vasculitis. Results are expressed as mean \% expression $\pm S D$. There was a significant increase in IL2-R expression in patients with idiopathic retinal vasculitis, as demonstrated by flow cytometry $(p<0.05)$.

Table IV. IL2-R expression on peripheral T-lymphocytes in patients receiving CsA therapy

\begin{tabular}{cc}
\hline \multicolumn{2}{c}{$\%$ IL2-R expression $( \pm \mathrm{SD})$} \\
\cline { 2 - 2 } Pre-treatment & Post-treatment \\
\hline $33.2 \pm 6$ & $22.6 \pm 10$ \\
$(8.4 \pm 5.6)$ & $(8.4 \pm 5.6)$ \\
\hline
\end{tabular}

Patients receiving CsA $(n=4)$ demonstrated a mean reduction in IL2-R expression after only 3 months of treatment. On treatment the IL2-R expression was still greater than control values (in parentheses).

with foreign antigen expression are integral in the activation of the immune system. Expression of class II antigens by lymphocytes is normally restricted to B-cells and occurs on activated T-cells only. Quiescent T-cells stimulated by specific antigen by antigen presenting cells also express receptors for IL2 and will proliferate to autocrine or exogenous IL2. IL2-R expression is maintained only in the presence of IL2. The common leucocyte antigen CD45 $\mathrm{R}$ has three isoforms. CD45-RO cell surface expression occurs on maturation of naive to memory cells, as a signal of activation, and is thought to be a potential marker of activation in autoimmune disease. However, phenotype reversal to the common CD45-Ra phenotype is known to occur in mature memory cells, reducing the sensitivity of the marker.

We have demonstrated systemic activation of circulating T-lymphocytes with increased levels of IL2-R expression, in two separate cohorts of patients by APAAP and flow cytometric techniques. The increase in expression of IL2-R by flow cytometry compared with APAAP may be explained by the larger cell sampling size and better staining characteristics employed by this technique. None of these patients had signs of systemic disease, either clinically or by standard laboratory testing (uveitis screen). We also observed increased HLA-DR expression in lymphocytes in group A patients studied by APAAP but not in group B patients studied by flow cytometry. We believe this reflects differences in the sensitivity of the techniques used. APAAP detects both cytoplasmic and membrane expression, whilst flow cytometry measures only cell surface fluorescence and the negative findings in flow cytometry are representative of the high background levels accounted for when the parameters are set. No difference was found in CD45-RO expression in either test, confirming the limited usefulness of this antigen as a systemic marker of immune activation in organspecific autoimmune disease. Systemic T-cell activation in uveitis has been found in a previous study using flow cytometric analysis, ${ }^{10}$ but the sample group contained patients with systemic disease, in whom activation of circulating T-cells might be expected from the underlying immunopathology of the disease processes. In our two cohorts of patients the treated and untreated patients were grouped together, which may have masked potential differences in activation marker expression.

This study, in accordance with others, ${ }^{8}$ further demonstrated that CD8 and CD4 levels are unhelpful parameters when assessing idiopathic uveitis. We could not confirm an abnormal CD4:CD8 ratio in uveitis patients with the two assays used.

In our second group of patients we demonstrated an increased IL2-R expression in patients with retinal vasculitis compared with other patients and controls. This increased expression, however, bore no significant correlation with disease activity as assessed by a recently described uveitis scoring system. ${ }^{17}$ An explanation of this may lie in the fact that the new uveitis scoring system details the extent of the disease but does not account for the severity of retinochoroidal inflammation. In this study we have observed that the more severe the retinal vasculitis, the greater the likelihood of identifying activated lymphocytes in the circulation. Recent work has demonstrated activated T-cells in patients with systemic immune-mediated disease but not in idiopathic uveitis. ${ }^{18}$ Although there was no clinical evidence of systemic vasculitis in patients described in this study, further long-term follow-up will reveal whether these patients represent a subgroup of systemic vasculitic syndromes, a spectrum of disease that may present with predominant ocular signs, akin to sarcoid or Bechçet's disease. ${ }^{19}$ It should be emphasised that dual flow cytometric analysis (Fig. 2) in this study confirmed the increased expression of the CD4+,IL2 - R+ phenotype, supporting the notion of a T-cell-mediated mechanism of the disease. ${ }^{2}$

In a small subgroup of patients who were tested before and after commencing CsA therapy we observed a $32 \%$ reduction in IL2-R expression. This would be expected as an indirect consequence of the drug's action on the inhibition of IL2- mRNA ${ }^{20}$ and subsequent reduction in amplification of the T-cell response and IL2-R expression. CsA therapy, however, only partially reduced IL2-R levels, and further follow-up of these patients is required to assess whether the IL2-R becomes fully suppressed or whether IL2-R expression blockade by CsA is being circumvented by alternative pathways of T-cell activation. At present, the findings support the view that these observations represent real changes in the circulating T-cell phenotype with disease, and the corollary that this test may be used as 
a monitor of immunosuppression. We have not, however, longitudinally studied the effect of steroid therapy alone on activation marker expression.

We also studied peripheral lymphocyte expression of $\gamma \delta+$ T-cell and CD5+ B(CD19) cells. B-lymphocytes expressing the T-cell-associated antigen CD5 and T-cells bearing $\gamma \delta$ antigen receptor form only a minor population of the adult lymphoid pool, but are the major population in the neonatal lymphoid pool. Their functions are largely unknown, but are speculated as playing an important role in the development of self tolerance in the neonate and autoantibody formation and T-cell cytotoxicity at the site of inflammation in adults. ${ }^{21,22}$ Recent studies suggest that CD5+ B-cells act as a marker of activation, rather than an indicator of cells producing autoantibodies. ${ }^{23}$ Although this phenotype is raised in the systemic circulation of other autoimmune diseases, ${ }^{24}$ we were unable to confirm a significant rise in our group of patients. These cells, however, may still be generated locally, but again in such numbers that precludes identification by present tests.

The present and previous studies thus provide evidence for systemic T-lymphocyte activation in idiopathic uveoretinitis and uveitis with concomitant systemic disease. The sensitivity and selectivity of present tests for autoreactivity do not permit accurate monitoring of antigenspecific T-cells. The potential application of this study is still limited, however, by the inability to correlate activation marker expression with our present grading methods of clinical activity. There still remains a strong need for more accurate documentation and monitoring of the degree of immunosuppression during treatment.

Although only 4 patients were studied, we have demonstrated that IL2-R expression may be an indicator not only of systemic activation but to active immunosuppression with CsA therapy in retinal vasculitis patients, the mechanism of which has been discussed. If the sensitivity of the above assays could be increased then the future application of such monitoring would enhance the efficacy of present treatment modalities such as CsA and future immunotherapeutic measures that are also aimed at inhibition of secondary amplification of the immune response (cf. FK506). ${ }^{25}$

This project was supported by grants from the Scottish Home and Health Board and Grampian Health Board. We would like to acknowledge the expert assistance of $\mathrm{Mr}$ Jim Milton with the flow cytometric analysis.

Key words: APAAP immunocytochemistry, Cyclosporin A (CsA), Endogenous posterior uveitis, Flow cytometry, Interleukin 2 receptor (Il2-R).

\section{REFERENCES}

1. Forrester JV: Endogenous posterior uveitis. Br J Ophthalmol 1990, 74: 620-3.

2. Forrester JV, Liversidge J, Dua HS, Towler H, McMenamin PG: Comparison of clinical and experimental uveitis. Curr Eye Res 1990, 9 Suppl: 75-84.

3. Wacker WB, Donoso LA, Kalsow LM, Yakendo JA, Organisciak DT: Experimental allergic uveoretinitis: isolation, characterisation of a soluble uveitopathogenic antigen from bovine retina. J Immunol 1977, 119: 1949-58.
4. Kauhn LS, Sclaegel TF, Weber JC, Bregal A: Serum immunologlobulins and uveitis. Arch Ophthalmol 1983, 101: 458-9.

5. Char DH, Christenson M, Stein P, Massi R: Serum immune complexes in uveitis. Am J Ophthalmol 1979, 87: 679-81.

6. Forrester JV, Stott D, Hercus K: Naturally occurring autoantibodies to bovine and human retinal $\mathrm{S}$ antigen: a comparison between uveitis patients and healthy volunteers. $\mathrm{Br}$ J Ophthalmol 1989, 73: 155-9.

7. deSmet MD, Yakamoto JH, Mochizuki M, Gery I, Singh VK, Shinohara T, et al. Cellular immune responses of patients with uveitis to retinal antigens and their fragments. Am J Ophthalmol 1990, 110: 135-42.

8. Dechennes J, Freeman WR, Char DH, Garavoy MR: Lymphocyte subpopulations in uveitis. Arch Ophthalmol 1986, 104: $233-6$

9. Froebel KS, Armstrong SS, Cliffe AM, Urbaniak SJ, Forrester JV: An investigation of the general immune status and specific immune responsiveness to retinal $S$ antigen in patients with chronic posterior uveitis. Eye 1989, 3: 263-70.

10. Deschennes J, Char DH, Kalita S. Activated T-lymphocytes in uveitis. Br J Ophthalmol 1986, 72: 83-7.

11. Liversidge J, Sewell H, Forrester JV: Interactions between lymphocytes and cells of the blood retinal barrier: mechanisms of T-cell adhesion to human capillary endothelial cells in vitro. Immunology 1990, 71: 390-6.

12. Nussenblatt RB, Palestine SG, Chan CC: Cyclosporin A therapy in the treatment of intraocular inflammation resistant to systemic steroids and cytotoxic agents. Am J Ophthalmol 1983, 96: 275-82.

13. Towler HM, Cliffe AM, Whiting PH, Forrester JV: Low dose cyclosporin A therapy in chronic posterior uveitis. Eye 1989, 3: 282-7.

14. Towler HM, Whiting PH, Forrester JV: Combination of low dose cyclosporin and steroid treatment in chronic intraocular inflammation. Eye 1990, 4: 514-20.

15. Nussenblatt RB, Rodrigues MM, Walker WB, et al. Cyclosporin A inhibition of experimental allergic uveoretinitis in lewis rats. J Clin Invest 1987, 67: 1228-31.

16. Nussenblatt RB, Palestine AG, Chan CC, Roberge F: Standardisation of vitreal inflammatory activity in intermediate and posterior uveitis. Ophthalmology 1985, 92: 467-71.

17. BenEzra D, Forrester JV, Nussenblatt RB, Tabbara K, Timonen P: Uveitis scoring system. Springer-Verlag, Berlin, 1991.

18. Feron E, Calder V, Lightman S: Distribution of IL2-R and CD45RO expression on CD4+ and CD8+ T-lymphocytes in posterior uveitis using 3-colour flow cytometric analysis. International symposium on recent developments in the immunopathology of intraocular inflammation [Abstract], 1991:37.

19. BenEzra D, Nussenblatt RB: Ocular manifestations of Behçets disease. J Oral Pathol 1978, 7: 431-42.

20. Granelli-Piperno A: In situ hybridisation for interleukin 2 and interleukin 2 receptor mRNA in T-cells activated in the presence or absence of CsA. J Exp Med 1988, 5: 1649-58.

21. Kearney JF, Vakil M: Idiotype-directed interaction during ontogeny plays a major role in the establishment of the adult B cell repertoire. Immunol Rev 1986, 94: 39-50.

22. Janeway CA, Jones B, Hayday A. Specificity and function of T-cells bearing receptors. Immunol Today 1988, 9: 73-6.

23. Vernino LA, Pisetsky DS, Lipsky PE: Analysis of the expression of CD5 by human B cells and correlation with functional activity. Cellular Immunol 1992, 139: 185-97.

24. Plater-Zyberk C, Brennan FM, Feldmann M, Maini RN: Fetal type B and T lymphocytes in rheumatoid arthritis and primary Sjögrens syndrome. In: Feldmann M, Maini RN, Woody $\mathrm{R}$, eds. T-cell Activation in Health and Disease. London: Academic Press, 1989: 233-43.

25. Thomson AW: FK506 enters the clinic. Immunol Today. 1990, 11: 35-6. 